EDITOR'S
CHOICE

Correspondence to

Jorn Sonderholm;

jorn13@gmail.com

Received 4 September 2009 Revised 28 October 2009 Accepted 23 November 2009

\title{
A theoretical flaw in the advance market commitment idea
}

\author{
Jorn Sonderholm
}

\begin{abstract}
Infectious and parasitic diseases cause massive health problems in the developing world. Research and development of drugs for diseases that mainly affect poor people in developing countries is limited. The advance market commitment (AMC) idea is an incentivising mechanism for research and development of drugs for neglected diseases. Discussion of the AMC idea is of renewed interest given the launch in June 2009 of the first AMC. This pilot AMC is designed to, among other things, test the idea for potential future applications. This paper is a critique of the AMC idea. It seeks to show that the idea has a hitherto unrecognised theoretical flaw that should make policy-makers and donors hesitant to embrace future applications of the idea.
\end{abstract}

\section{INTRODUCTION}

Infectious and parasitic diseases cause massive health problems in the developing world, whereas they leave the developed one relatively unscathed. ${ }^{1}$ Research and development ( $\& \& D$ ) of drugs for diseases that mainly affect people in developing countries is very limited. According to one study, fewer than $1 \%$ of the 1223 new medicines launched on the international market between 1975 and 1997 were destined specifically for tropical communicable diseases. ${ }^{2}$ The primary reason for the scarcity of $R \& D$ of drugs for diseases that mainly affect people in developing countries is that many poor people do not have sufficient money to pay for drugs for their ailments. For-profit pharmaceutical companies therefore have little economic incentive to invest resources in the $R \& D$ of drugs for diseases that predominantly affect the global poor, and as a result it has become common to think of them as 'neglected diseases'. The problem that so few drugs are available for diseases that cause an enormous burden of disease (predominantly) in the developing world is sometimes called the 'availability problem'.

In the last decade, the availability problem has received considerable attention from academics, policy-makers and members from the nongovernmental organisation and think-tank sectors. A number of proposals have been fielded as to how the scope of this problem might be minimised. The advance market commitment (AMC) idea is one such proposal. The idea was first introduced by Michael Kremer in $2001^{4}$ and was further refined in a 2004 book coauthored with Rachel Glennerster. $^{6}$ In 2005, the think tank Center for Global Development (CGD) issued a report in which the AMC idea was discussed in detail and in which a recommendation was made to the international donor community to implement the idea. ${ }^{7}$ Discussion of the AMC idea is of renewed interest given recent developments in the international donor community. In June 2009, the Global Alliance for Vaccines and Immunisation (GAVI), the World Bank, WHO, Unicef, the Bill \& Melinda Gates Foundation and the national governments of Italy, Canada, Russia, Norway and the UK formally launched the first ever AMC. This pilot AMC is designed to accelerate development of vaccines that meet the needs of developing countries, bring forward the availability of effective pneumo vaccines (through scaling up of production capacity), accelerate vaccine uptake (through predictable vaccine pricing for countries and manufacturers) and test the AMC idea for potential future applications. ${ }^{8}$

This paper is a critique of the AMC idea. It seeks to show that the idea has a hitherto unrecognised theoretical flaw that should make policy-makers and donors hesitant to embrace any future applications of the idea. (Others have also criticised the AMC idea. $)^{9-11}$ The focus of discussion is the AMC idea as developed in the 2004 book by Kremer and Glennerster and the 2005 CGD report. These works provide the key theoretical underpinnings upon which the 2009 pilot AMC is based.

In the next section, the AMC idea is presented and placed in context with a competing prize proposal for how to incentivise R\&D of drugs for neglected diseases. In the third section, the objection to the AMC idea is presented and discussed, and the fourth section contains some brief final remarks.

\section{ADVANCE MARKET COMMITMENTS}

The fundamental characteristics of an AMC are as follows: a donor (or a number of such) makes a legally binding commitment to heavily subsidise the future purchase of a set amount of a medical drug that is not yet fully developed. The donor commitment presupposes three things: that the drug meets the medical target product profile (including effectiveness and public health impact), that there is demand for the drug and that for-profit pharmaceutical companies that have signed a guarantee and supply agreement with the donor(s) must offer a lower, long-term 'tail price' after the funds of the AMC are depleted. An AMC can be used both for late-stage products (those in the final stages of regulatory approval and for which manufacturing capacity is being established) and for early-stage products (those requiring scientific progress and extensive testing of candidate medicines). ${ }^{7}$

CGD's development of the AMC idea involves both a late-stage and an early-stage AMC. The earlystage AMC is for a malaria vaccine. One of its 
important details is that donors promise to pay US\$14 of the cost of up to 200 million treatments at a guaranteed price of US\$15 per treatment. The buyers of the malaria vaccine are developingcountry governments that will contribute US\$1 per treatment (for the first 200 million treatments). ${ }^{\mathrm{i}}$ In return for being given the opportunity to sell their product at US\$15 per treatment, which is a price that constitutes a huge mark-up on the cost of production, for-profit pharmaceutical companies promise to provide further treatments (after the initial 200 million treatments) at a sustainable base price that reflects the cost of production (about US\$1 per treatment). An independent adjudication committee (IAC) will determine the technical specification of the vaccine together with the question of which products meet this specification. Finally, and very importantly, if a company develops a second-generation, medically superior product (as verified by the IAC), this product will also be eligible for the price guarantee. The price guarantee will apply to the first 200 million treatments bought, shared among the eligible products according to demand.

In their development of the AMC idea, CGD emphasises that what is being created is a market and not a prize. ${ }^{7}$ The reason for this emphasis is that the AMC idea is compatible with a design in which donors commit to subsidising the purchase of a set quantity of treatments of a future drug from the company that first develops a drug that meets the medical target profile. Under this design option, an AMC functions much like a prize mechanism in which a monetary prize is awarded to the pharmaceutical company that first develops and brings to market a drug with the required medical profile. The idea of using monetary prizes to stimulate $\mathrm{R} \& \mathrm{D}$ of pharmaceutical products is popular among contemporary theorists. ${ }^{12-15}$

CGD is eager to avoid an AMC design that resembles a prize mechanism. The reason for this is that such a mechanism is vulnerable to a number of objections, prominent among which is what might be labeled the 'winner-takes-all' objection. The fact that a prize mechanism only awards a prize to the company that first reaches a specific pharmaceutical goal adds significant risk and uncertainty to companies that are entertaining the idea of engaging in $\mathrm{R} \& \mathrm{D}$ of the specified product. The usual uncertainties that for-profit pharmaceutical companies have about whether or not their basic research will pan out and whether or not the various stages of clinical trials will be successful are now conjoined with the risk of not knowing whether or not they will win the race against competing companies in terms of being the company that first wins regulatory approval of a drug with the specified properties. Drug development is expensive, and it is therefore very undesirable for a company to enter into, and take second place in, a race in which the winner takes all. A commonly cited estimate of the cost of bringing a new drug to market puts the cost at US\$800 million. ${ }^{16}$

Three other, well-known problems with a prize mechanism should also be mentioned. First, by making a commitment to award a prize to the company that first develops a particular kind of drug, the donors do not guard themselves against the possibility that at time $t$ in the future when the prize is awarded, there is no demand for the product. For example, when an effective vaccine for malaria is developed, there might not be any demand for such a vaccine because the diseases has been eradicated through other means such as extended use of improved bednets and/or extended spraying with improved insecticide.

\footnotetext{
'The pilot AMC launched by GAVI and partners sets the price per dose for an eligible vaccine at US\$7.
}

Second, a prize mechanism offers very strong incentives to for-profit companies to meet the target profile of the required drug but only weak incentives to develop a drug that exceeds the target profile or a useful drug that does not quite meet that profile. This second point of criticism has also been levelled against an AMC scheme that creates a prize and not a market. ${ }^{9}$

Third, a prize mechanism does not offer any incentives to produce second-generation drugs for medical condition $\mathrm{x}$ once the first-entry drug for $\mathrm{x}$ has been awarded a prize. ${ }^{9}$

It is instructive to briefly go through how CGD's AMC design avoids these four problems that mar a prize proposal. This enables one to appreciate the significant strengths of an AMC scheme. First, there is no winner-takes-all problem, because the proposed AMC creates a market in which several for-profit companies can compete for eligible funds. Donors have not committed themselves to heavily subsidise a specific quantity of the first developed drug that meets the specifications set up by the IAC. Second, there is no problem with a potential lack of demand at time $t$ in the future when a drug is developed. By making it clear that they will only subsidise the purchase of drugs for which there is a demand, donors avoid the problem of locking themselves into a legally binding commitment to spend money on a pharmaceutical product that nobody wants. ${ }^{7}$

Third, in virtue of creating a market in which new and medically superior products can compete for funding with initial market entrants that merely meet the initial target specifications, an AMC avoids the problem of not providing an incentive to develop and bring to market products that exceed the target profile as initially described by the IAC. ${ }^{7}$ Fourth, for reasons similar to the ones mentioned in connection with the previous point, the AMC cannot be criticised for not providing incentives to develop second-generation drugs for medical condition $\mathrm{x}$ once the firstentry drug for $\mathrm{x}$ has been approved for funding by the donors.

\section{THE PROBLEM}

An AMC scheme prohibits 'me-too' drugs. Every new drug entrant is therefore a significant medical improvement over the incumbent one(s). ${ }^{7}$ CGD allows, however, for the possibility that several different products will be licensed at about the same time within the first year of an AMC. It is suggested that in a scenario such as this, it would be sensible to allow the different products to share the market at the outset. To achieve this, the AMC could allow a window of one year from the entry time of the first entry drug within which second-qualifying products would be eligible for the guarantee without having to demonstrate medical superiority. ${ }^{7}$

Consider now a scenario in which several products have been licensed under an AMC scheme. Moreover, assume that at least one of these products has been licensed more than one year after the time of license of the initial AMC-approved product. On this assumption, one product is medically significantly superior to the other one(s) in the scheme. What will product demand be in a scenario such as this? It is not obvious that governments of developing countries will always choose the medically superior product even though this is priced at a level identical to that of inferior (but licensed) ones. ${ }^{\text {ii }}$ Perhaps the medically superior product has side effects that are culturally offensive in certain developing countries. The CGD report highlights the possibility of governments rejecting a medically superior product for

ii CGD is eager to design an AMC scheme in which there are strong incentives to always buy the best available medicines. From the point of view of CGD, it is a suboptimal outcome if the best available medicines are not the ones that are purchased. 
non-medical reasons. "For example, if a vaccine generated side effects that were medically harmless but culturally unacceptable, there might be an unwillingness to use the vaccine."7 Because an AMC scheme is demand driven, it compels the donors to fund the purchase of medically inferior products when it is such products that are in demand by developing world governments. This theoretical feature of an AMC scheme is an unattractive one that should make policy-makers and donors hesitant about signing up to it.

The problem identified here is not just a theoretical one. Consider this example: $\mathrm{A}$ is a first-generation vaccine against disease $\mathrm{x}$. Vaccine $\mathrm{A}$ has an efficacy rate of $60 \%$ and an immunisation period of 10 years. Moreover, A does not contain porcine (pig) gelatin. Vaccine $B$ is a second-generation vaccine against disease $\mathrm{x}$. It has an efficacy rate of $90 \%$ and the immunisation period is lifelong. Moreover, like many vaccines currently on the market, B contains porcine gelatin. As recognised by the Australian government's Department of Health and Ageing, some members of the Islamic and Jewish faiths may object to some types of vaccination on the grounds that they contain pork products. ${ }^{17}$ Given this, it is by no means just a theoretical possibility that were $B$ to become available on the market, some governments would reject B for cultural or religious reasons and continue to demand the medically inferior product, A. The issue of whether it is permissible for observant Muslims and observant Jews to receive vaccinations that contain porcine gelatin is so pressing that WHO has found it worthwhile to release a statement in which a select group of notabilities from within the two religious groups express approval of the use of vaccines containing porcine gelatin. ${ }^{18}$ The issue of permissibility is, however, contested. Reacting to news that one of the two triple measles, mumps and rubella (MMR) vaccines used by general practitioners in Britain are made using porcine gelatin, Imam Habib Rauf (Glasgow Central Mosque) said, "I did not know it contained porcine gelatin. I have a threeyear-old child who was recently given the MMR vaccine and if I had known about this I would not have let my child have the vaccination" (Herald Scotland, 26 Jun 2003). Also, the former Malaysian Prime Minister Abdullah Haji Ahmad Badawi has argued that Malaysia and the developing world need to ensure self-sufficiency in halal vaccine production. ${ }^{19}$ The issue here is that some vaccines may contain traces of animal tissue from animals that have not been slaughtered according to appropriate religious rules. Such vaccines are therefore culturally or religiously unacceptable.

Why is it that the feature of an AMC scheme that it compels donors to fund the purchase of medically inferior products (when it is such products that are in demand by governments in the developing world) should make policy-makers and donors hesitant about signing up to it?

First, there is no reason why taxpayers in affluent countries should fund the acquisition of medically inferior products for cultural reasons when a medically superior product (as attested by the IAC) is available. Whatever these cultural reasons are (the CGD report offers no examples), they are by definition medically irrelevant. It is here worthwhile to remember that second-entry drugs must constitute a significant medical improvement compared to already existing ones. So, in cases in which a government chooses a medically inferior product, it is not just choosing a product that is medically inferior in some fairly benign sense. It is choosing a product that medically is significantly worse than another product that is available at the same price. A scheme that allows for this kind of practice is not sufficiently respectful towards those taxpayers who are funding the scheme. The scheme has a price tag of US\$3 billion. This is the amount of money that CGD suggests is set aside for an AMC for a malaria vaccine. ${ }^{7}$ The pilot AMC for a pneumococcus vaccine is funded at the level of US\$1.5 billion.

Two things should be kept in mind here. First, the co-payment that individual countries must make towards the purchase of products within an AMC scheme is in theory supposed to come from these countries themselves. However, this co-payment is in practice likely to be paid for by other donors. ${ }^{6}$ The individual countries that receive pharmaceutical products under an AMC scheme are therefore likely to receive products that are fully paid for by donors (the majority of which are tax funded). Second, available monetary resources within the international donor community for health interventions are finite. As a result of this, donor funds spent on the acquisition of inferior products for cultural reasons in an AMC scheme is money that is taken away from other health interventions many of which benefit (or have great potential to benefit) populations that have no strong cultural sensitivities and are willing to receive first-class medical care offered to them free of charge.

Moreover, it is difficult to see how an AMC scheme that allows for the funding of medically inferior products is compatible with those principles of 'no waste of donor resources' and 'only paying for results' that currently are much in vogue in the donor community and developing-world aid sector. CGD endorses these principles at a number of places in its report. ${ }^{7}$ It is a waste of donor resources to fund the acquisition of significantly inferior pharmaceutical products. Also, the result one is paying for is that numerous people in the developing world will receive significantly suboptimal medical treatment as compared with what they would have received if they had been willing to disregard their particular and medically irrelevant cultural outlook. Of course, if the baseline scenario is one in which no one receives treatment because an individual government will not accept an alternative product if it does not get the inferior one it wants, then donors are paying for public health results by funding the purchase of an inferior product. Focusing on this baseline scenario, one might now say that if donors refuse to fund the purchase of medically inferior products for which there is demand, then donors are responsible for a public health situation that is worse than it otherwise could have been. The right reply to this is to say that responsibility for this unfortunate health outcome does not lie with the donors but with the individual governments (or individuals) that refuse to accept medically superior products offered to them free.

It is important to stress that governments' and individuals' right to refuse medical treatment for cultural reasons should be respected by donors and the taxpayers who fund them. This respect from donors and taxpayers does not, however, entail that they have an obligation to provide those who refused the initial offer with alternative means of treatment. In the preface to the CGD report, the president of CGD, Nancy Birdsall, writes, 'Adequate investment in global public goods should be a cornerstone of foreign assistance. By definition, we all benefit from global public goods, and we share responsibility to see that they are probably funded and available to everyone'. ${ }^{7}$ From this, it does not, however, follow that taxpayers in the developed world (or anyone else for that matter) have a responsibility to fund the purchase of inferior pharmaceutical products for cultural reasons. The type of responsibility Birdsall refers to can be discharged by only funding the purchase of the medically superior product in an AMC scheme.

If one finds the view expressed here overly harsh, then one should contemplate whether or not it is an appropriate use of 
country x's public funds to finance alternative and medically inferior means of treatment for those of its citizens who for cultural reasons do not wish to receive treatment that involves, say, blood transfusion, particular foodstuffs and/or interaction with healthcare personnel and/or patients of a particular gender, sexual orientation, race, religion, ethnicity, caste or tribe. If one is of the opinion that x's public funds should not be spent on accommodating the medical needs of citizens with these cultural preferences, then rejection of the view that an AMC should not fund the acquisition of inferior drugs for cultural reasons requires that one can point to a morally salient disanalogy between the two types of case. This is by no means an easy task.

Taxpayers in affluent countries also have few prudential reasons for funding the purchase of inferior pharmaceutical products by governments that reject the medically superior product for cultural reasons. A considerable amount of the payout from an AMC scheme goes towards the establishment and upkeep of significant production facilities for the subsidised products. The establishment and upkeep of such facilities are, however, items that taxpayers in affluent countries have few prudential reasons for funding when the end products of these facilities have no demand in the developed world. As pointed out by a number of commentators, medicines developed for diseases that are largely prevalent in the developing world are also of benefit to people in the developed one. ${ }^{7}$ For example, military personnel and travellers who depart for regions in which the diseases in question are prevalent benefit from having access to efficient medical protection against these diseases. These groups do not, however, have a need for medically inferior products that are in demand by certain governments for cultural reasons. Military personnel and travellers from the developed world do not in general share the cultural outlook that make the medically superior product unpalatable for some in the developing world. These groups have a need for, and generally demand, the medically best available product, and as a result of this, they and their fellow taxpayers have strong prudential reasons for only funding the establishment and upkeep of production facilities that deliver this product.

A second reason why the 'respect for non-medically motivated drug picks' feature of an AMC scheme is unattractive is that it makes the scheme wide open for gaming and influence through corrupt behaviour. CGD's claim that aid spent on R\&D for, and delivery of, vaccines through an AMC is low risk with few opportunities for corruption and rent-seeking is unsubstantiated. ${ }^{7}$ Since governments are under no obligation to demand the medically superior product and can allude to cultural and other nonmedical considerations as their motivations for demanding the product they do, pharmaceutical companies (and other interest groups) can lean on governments and make them demand the second- and third-best products in return for favours. ${ }^{\text {iii }}$

Governments can also contact pharmaceutical companies and suggest business deals that involve favours from pharmaceutical companies in return for a continued demand for their inferior products. Pharmaceutical company x can offer a host of things to government $y$ in return for $y$ continuing to demand (and/or $y$ putting political pressure on other governments to also demand) x's product rather than a medically superior product. The list of things that $x$ can offer $y$ include monetary gifts, rebates on other

\footnotetext{
iii Another example of a non-medical consideration that can influence the choice of product is that of a government that rejects the medically superior product because of the nationality of the company that produces the product. In such a case, a geopolitical consideration plays an illegitimate role when it comes to deciding which of several licensed products to demand.
}

drugs in x's portfolio, funding for projects with no public health benefits and direct investments. Kremer and Glennerster acknowledge that an AMC can be gamed and influenced through corruption. ${ }^{6}$ With regard to corruption, they suggest that companies that offer bribes should be punished, but their discussion offers no solutions as to how the possibilities for gaming outlined above can be blocked.

The most obvious way to block these possibilities for corrupt behaviour and gaming consists in bestowing the donors or the IAC or both with a right to put restrictions on what drugs can be demanded where several drugs have been licensed. Such a move is impossible, however, because it is blatantly inconsistent with one of the very keystones of an AMC scheme-namely, that it is demand driven. The broader theoretical problem is here that an AMC severs the link between those who pay for a product (the donors) and those who decide what product to purchase (governments). This problem is a rather serious one, since those who are given the opportunity to spend other people's money relatively freely do not always tend to do it wisely.

\section{ALTERNATIVES TO THE AMC IDEA}

Nothing in the above critique of the AMC idea implies indifference towards the suffering in the developing world that is brought about by neglected diseases. This suffering is truly horrendous, in both scope and severity, and organisations such as GAVI, the World Bank and CGD that work at a multitude of levels to alleviate it certainly deserve to be commended and respected for many of their efforts in this regard.

If one rejects the AMC idea as an attractive incentivising mechanism for R\&D of drugs for neglected diseases, is one then left with no other choice than just accepting (and deploring) the current state of affairs in which relatively little is done to develop and bring to market effective medicines of the kind in question? Luckily, the answer here is 'no'. A number of alternative incentivising mechanisms are on the table for further pursuit by academics, policy-makers and members from the NGO and think-tank sectors, and among these alternatives a better incentivising mechanism (or set of such) can be found. Wild-card patent extensions, patent extensions, cash prizes, the Health Impact Fund, various sorts of tax credits and priority review vouchers are examples of such proposals. These are discussed elsewhere. ${ }^{14} 15$ 20-23 My own view is that priority review vouchers constitute an attractive incentivising mechanism. My reasons for this view are spelled out elsewhere. ${ }^{24}$ iv

\section{Competing interests None.}

Provenance and peer review Not commissioned; externally peer reviewed.

\section{REFERENCES}

1. WHO. World Health Report. Changing history. Geneva: WHO, 2004

2. Trouiller $\mathbf{P}$, Torreele $E$, Olliaro $P$, et al. Drugs for neglected diseases: a failure of the market and a public health failure? Trop Med Int Health 2001;6:945-51.

3. Selgelid MJ. A full-pull program for the provision of pharmaceuticals: practical issues. Public Health Ethics 2008:134-45.

4. Kremer M. Creating markets for new vaccines. part I: rationale. In: Jaffe $A B$, ed Innovation policy and the economy. Cambridge: MIT Press, 2001:35-72.

5. Kremer M. Creating markets for new vaccines. part II: design issues. In: Jaffe $A B$ ed. Innovation policy and the economy. Cambridge: MIT Press, 2001:73-118.

6. Kremer M, Glennerster R. Strong medicine: creating incentives for pharmaceutical research on neglected diseases. Princeton: Princeton University Press, 2004

7. Barder 0, Kremer M, Levine $\mathrm{R}$, et al. Center for global d, advance market commitment working $G$. making markets for vaccines: from ideas to action. Washington DC, USA: Center for Global Development, 2005.

8. The Pneumococcal AMC. Ready to save lives. GAVI Alliance, 2007. http://www. vaccineamc.org/pneu_amc.html.

iv I would like to thank Jan Narveson and an anonymous referee from the Journal of Medical Ethics for helpful comments on an earlier version of this paper. 
9. Ravvin M. Incentivizing access and innovation for essential medicines: a survey of the problem and proposed solutions. Public Health Ethics 2008:110-23.

10. Hollis A. Drugs for neglected diseases: new incentives for innovation. In: Sloan F ed. Pharmaceutical innovation: incentives, competition, and cost-benefit analysis in international perspective. Cambridge: Cambridge University Press, 2007:75-90.

11. Berndt ER, Hurvitz JA. Vaccine advance-purchase agreements for low-income countries: Practical issues. Health Aff 2005:24:653-65.

12. Power E. Impact of antibiotic restrictions: the pharmaceutical perspective. Clin Microbiol Infect 2006;12:25-34.

13. Outterson K, Samora JB, Keller-Cuda K. Will longer antimicrobial patents improve global public health? Lancet Infect Dis 2007;7:559-66.

14. Stiglitz JE. Scrooge and intellectual property rights. BMJ 2006;333:1279.

15. Love J, Hubbard T. The big idea: prizes to stimulate R\&D for new medicines. Chic Kent law rev 2007:82:1519-54.

16. The tufts center for the study of drug development: Tufts University, 2009. http:// csdd.tufts.edu/index.php.
17. Myths and concerns about immunisation. Australian government, 2008. http://www.health.gov.au/internet/immunise/publishing.nsf/content/ 1FC63A2886238E6CCA2575BD001C80DC/\$File/myths-13-35.pdf.

18. Religious leaders approval of use of vaccines containing porcine gelatin: WHO, 2003 http://www.vaccinesafety.edu/Porcine-vaccineapproval.htm.

19. Fischer J. Religion, science and markets: European Molecular Biology Organization, 2008. http://fbae.org/2009/FBAE/website/images/PDF\%20files/Imporatant\% 20Publication/Religion\%20on\%20Foods.pdf.

20. Ridley DB, Grabowski HG, Moe JL. Developing drugs for developing Countries. Health Aff 2006;25:313-24.

21. Love J. Would cash prizes promote cheap drugs? London: New Scientist Magazine 2007:24-5.

22. Hollis A, Pogge T. The health impact fund: making new medicines accessible to all. Incentives for Global Health, 2008.

23. Spellberg B, Miller LG, Kuo MN, et al. Societal costs versus savings from wild-card patent extension legislation to spur critically needed antibiotic development. Infection 2007:35:167-74

24. Sonderholm J. In defense of priority review vouchers. Bioethics 2009:23:413-20. 